\section{Motivating prairie dogs}

\author{
ROBERT BOICE and JANET A. WITTER \\ University of Missouri, Columbia, Mo. 65201
}

Appetitive responding (double alternation and DRL) in tamed prairie dogs (Cynomys ludovicianus) was effected with food and water reinforcement. The result was generally inconsistent performance and/or death by starvation or dehydration. While wild prairie dogs did not need drinking water, tamed captives became vitally dependent. This need was met by operant responding only when terms of work were easy; when the terms of work were moderately difficult, some prairie dogs stopped responding and then died of dehydration.

Lockard's recent (1968) and provocative article is symptomatic of a movement by some comparative psychologists away from fixation on the albino rat. The present study depicts one such move with what appears, at first glance, to be an ideal rat substitute, the prairie dog.

Much of the basic literature on prairie dogs (Cynomys) is confined to three monographs (King, 1955; Smith, 1958; Koford, 1958). Each author depicts prairie dogs in terms that suggest an organism well suited for laboratory research; each has had extensive acquaintance with both field and pet specimens. King pioneered interest in the remarkable gregariousness and other social behaviors of Cynomys. He also found prairie dogs to be affectionate captives. 1 Smith noted that prairie dogs are "remarkably curious" and Koford added intelligence, responsiveness, and cleanliness to their attributes as captives.

As rodents adapted to semiarid habitats, prairie dogs can meet water needs without drinking. Thus they may urinate little and eliminate dry bolluses, making maintenance easy. They can be housed in any large gnaw-proof cage, and if afforded a window, they will spend much time apparently watching laboratory activities. A life span of up to 8 years in captivity (Young, 1946) and an "intelligent" appearance suggest that this slightly oversized squirrel is a rodent analogous to a small primate as a laboratory preparation. Cooperative behaviors are salient in laboratory study (Anthony, 1955). Cain \& Carlson (1968) conclude that these " . . diurnal sciurids make excellent laboratory animals and are easily trained using operant conditioning procedures [p. 185]."

The purpose of the present study was to explore the effects of conventional operant techniques in controlling prairie dog

*Paper presented at the 1970 meetings of the Southwestern Psychological Association, St. Louis. We thank Richard D. Millar for apparatus assistance and Paul Pavlish and Mary Brocmmelsiek for assistance in handling Ss. responding. Of necessity special attention was directed to motivational problems.

\section{SUBJECTS}

The Ss were two male and two female prairie dogs (Cynomys ludovicianus) live-trapped in Texas in 1967. They were estimated (Johnson, 1927) to be 60-70 days old. They were, except as noted, group housed in a canine cage and supplied with Lab Chow, ${ }^{2}$ carrots, lettuce, and sunflower seeds. Nesting material was seemingly preferred but endured only when consisting of tough fabrics.

\section{PROCEDURES}

Handling by undergraduate assistants was scheduled two or three times a week until the dogs were judged docile. This took at least a year and required that the nunt of the lot (Mange) be kept at home by "therapy."3

A major portion of Year 2 was spent in attempting to train the $\mathrm{Ss}$ in a wooden-block 8 -maze $(12 \times 32 \mathrm{~m})$ with a sunflower seed reward. The prairie dogs were food deprived by allowing access to a variety of foods for $1 \mathrm{~h}$ per day. The goal of this experiment was to effect double-alternation behavior. One male did not survive the deprivation regimen.

The three surviving prairie dogs, plus four additional untamed prairie dogs, were then observed daily for 2 months in a large enclosure with cement-block walls and a sand substrate. All Ss were surprisingly adept at climbing, and one untamed dog was lost to the depths of the laboratory walls.

During Year 3 the tamed Ss had no drinking water in their home cage but had access each day to water in an operant chamber. The chamber had a grid floor, stainless-steel sides $(50 \times 41 \times 43 \mathrm{~cm})$ and a Plexiglass top with a masking-noise speaker. The top was covered after training began, since the dogs persisted in standing to look out rather than barpressing. Water was presented via a mechanical dipper (capacity $=0.1 \mathrm{cc}$ ), the opening for which $($ diam $=3.5 \mathrm{~cm})$ was $10 \mathrm{~cm}$ from the floor. the second author for intensive
A standard rat lever (Lehigh Valley No. 1352) was mounted $14 \mathrm{~cm}$ from floor level and $65 \mathrm{~cm}$ to the left of the dipper hole. Sessions lasted $1 / 2 \mathrm{~h}$ per day.

Dipper training and response shaping were completed almost immediately. Brief training with continuous reinforcement was followed by some 60 sessions of fixed-interval (FI) scheduling. Interval length increased from $5 \mathrm{sec}$ to $120 \mathrm{sec}$ as individual $\mathrm{Ss}$ economized responses to reinforcements in a somewhat stable fashion (Fig. 1). Next, some 120 sessions of DRL (for differential reinforcement of low rate) scheduling were implemented with a similar ambiguity of planning. The response-reinforcement interval was minimal at $5 \mathrm{sec}$ and was (theoretically) increased by $5 \mathrm{sec}$ when the reinforcement to response ratio exceeded 0.75 . Individual variance and apparent limits in performance necessitated more subjective criteria. The interval was decreased late in training (Fig. 2) to permit evaluation of learning/performance factors. When dogs responded minimally (e.g., slept through the session), they were given supplemental water.

\section{RESULTS AND DISCUSSION}

The prairie dogs did not master the first a 1 ternation of the planned double-alternation task in over 500 trials. One $\mathrm{S}$ died from starvation and the others had apparent difficulty in adjusting to the l-h access regimen; eating during this time was inconsistent. When overdeprived, the dogs were sluggish and could not be induced to perform in the maze. Conversely, when apparently underdeprived, they spent considerable time in the maze chewing the walls and exploring. Similar competing behaviors in a maze have been reported in another xeric rodent, the gerbil (Reynierse, Scavio, \&

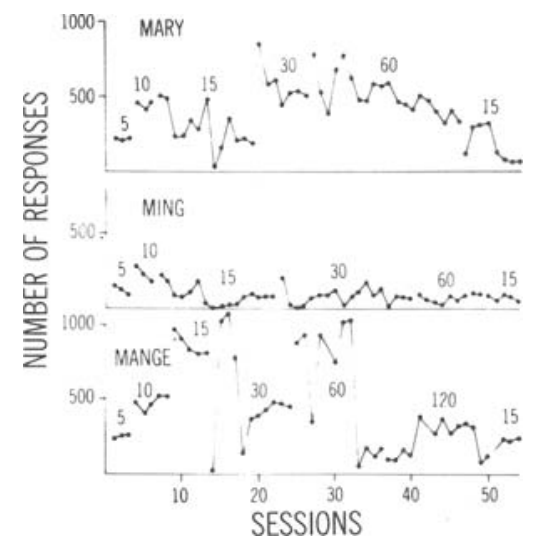

Fig. 1. Fixed-interval (FI) responding over sessions with 50 reinforcements possible per session. Interval lengths (seconds) are indicated next to respective functions. 


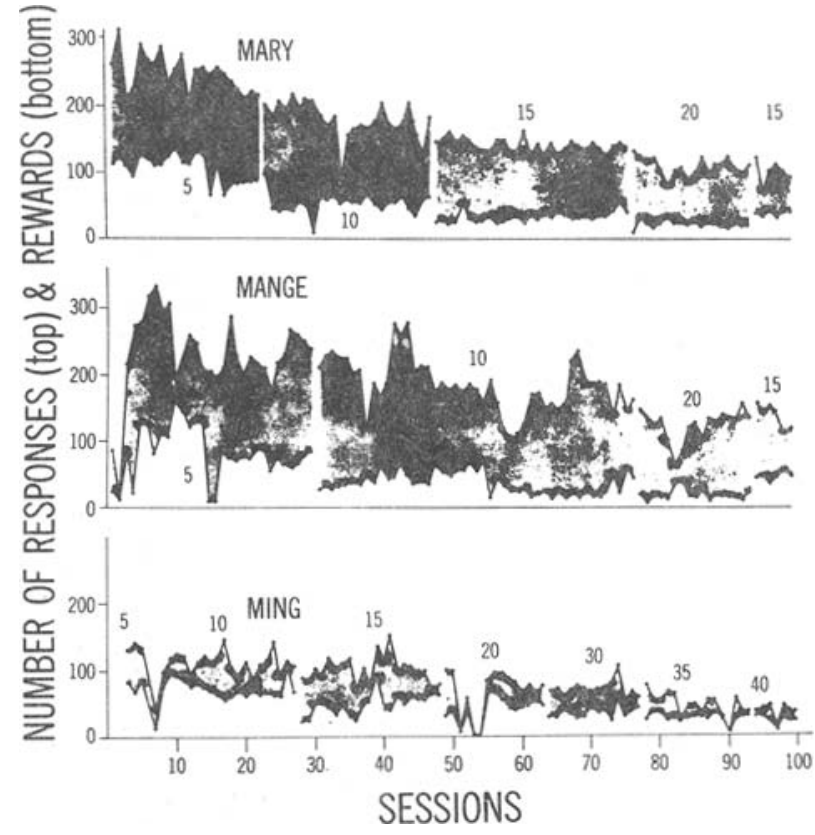

Fig. 2. DRL responding (top function in each graph) and rewards (bottom function in each graph). Minimal responsereward intervals (seconds) are indicated next to respective functions. Narrowness of shaded area represents relative efficiency of response patterns.

Spanier, 1970). Periods of consistent performance gave little hope that the dogs could learn the alternation problem. In any case, it was apparent that food deprivation was problematic, and we were led to attempt water deprivation as a motivator. Since prairie dogs are reputed to be relatively independent of water need, we expected that water deprivation would not induce torpor. Among others, King has noted the ability of wild Cynomys to exist on food moisture and metabolic water: "They never were observed to drink any of the free water which was occasionally present for a short time after a rainfall in the summer. When I placed water out for them, they quickly filled the vessel containing it with dirt [p. 34]."

Our preliminary observations in this regard were based on the behaviors of the dogs in the large enclosure. Water, in a dish, was provided at irregular intervals, succulents continued to be freely available. In the first instance Ming (female) and Mange (female) seemed eager for the water and Mary (male) ignored it. On the second occasion all drank but, as before, there was no apparent competitiveness involved. When the dish was left overnight it was always overturned. In subsequent instances the water was largely ignored.

Observations of behavior in the group situation generally agreed with those of Anthony (1955). Additions of note are mentioned briefly: noticeable effect. the head occurred. passive.

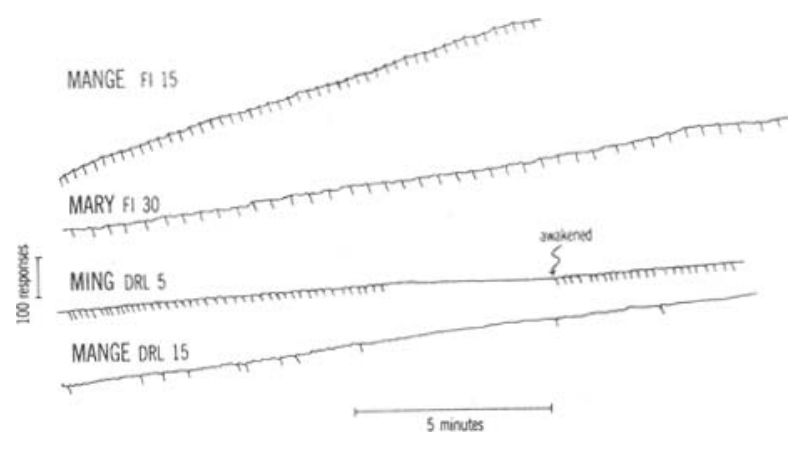

Fig. 3. Portions of cumulative records for individual $S s$ : (1) Mange FI 15-FI 15-sec responding with slight scalloping (total for session $=335$ responses and 50 reinforcements) (2) Mary FI 30-similar to (1) (total $=240$ responses and 50 reinforcements); (3) Ming DRL5-responding interrupted by sleep (total $=79$ responses and 77 reinforcements) (4) Mange DRL15 - "frustrated" responding (total $=232$ responses and 14 reinforcements).

Activity and Dormancy

Dormancy was not systematically observed in winter months, although housing in small enclosures had a soporific effect any time of year.

\section{Agonistic Behaviors}

They are able to climb a cement-block wall with ease. This ability seems limited to situations where the claws can be used to hang or push laterally and not where clasping with the legs is required. We once provided them with a "Jungle Jim" set of horizontal poles that was readily climbed but with some awkwardness. Repeated falls to the cage floor where, for example, the head struck a hard object, had no

\section{Burrowing}

The sand $(15 \mathrm{~cm}$ deep) did not permit actual burrows, but the dogs spent much time digging and "scooting" in channels next to walls. They often showed apparent burrow-construction activities in locations (e.g., flat wooden surfaces) without dirt. Most common was patting a surface with the top of the head. When on a bed with covers, Mange constructed a "burrow system" on top of the covers with two "entrances." Digging of nonexistent dirt preceded pushing movements to the entrance area where patting motions with

Reproductive Activity

Mary (male) frequently mounted Mange (female), as did Ming (female), but Mange did not appear to be receptive to either. Attempted mounts elicited a quick turnabout and biting in Mange. Ming was, when occasionally mounted by Mary,
Fights, which were mostly playful, were frequently preceded by "kissing." Most fights were initiated by Mary, who was once observed to attack Ming and Mange 20 times in a $25-\mathrm{min}$ period. Overall, agonism dominated to an extent suggesting that this situation produced excessively artifactual behaviors.

\section{Effect of Taming}

The untamed dogs remained huddled and immobile with an $O$ near, even with $O$ quiet and behind a blind for hours.

In operant training, FI responding was most economical by Ming (Fig. 1). Her performance was sometimes disrupted in sessions where she slept. Mary showed a more systematic tendency to reduce responding within interval values than Mange, but both were subject to marked variability. The tendency of Mange to respond at excessive rates is represented in Fig. 1. Exclusion of responding to the terminal portions of the interval (scalloping) was only minimal (Fig. 3). Fixed-interval responding did suggest that prairie dogs would perform to obtain water. However, laboratory rats in an analogous situation are comparatively superior; the FI situation for prairie dogs was seemingly obscured by overresponding. Thus a DRL schedule that reinforced moderate periods of nonresponding was used to produce evidence of discriminatory ability. 
Table 1

Amount (cc) of Water Earned in Second Day of Each 3-Day Stage of FR Terms

\begin{tabular}{rrrrrrrr}
\hline & \multicolumn{5}{c}{ FR } & \multicolumn{3}{c}{ Value (Terms) } \\
\cline { 2 - 7 } & \multicolumn{1}{c}{1} & 2 & 4 & 8 & 16 & 32 \\
\hline Ming & 51 & 99 & 78 & 65 & 16 & 0 \\
Mary & 106 & 46 & 51 & 33 & 18 & 16 \\
\hline
\end{tabular}

The progress of responding under DRL schedules was again favorable (i.e., comparable to that of rats and hamsters) only in the case of Ming (Fig. 2). Her performance was marred by sleeping in this situation. Sessions where Ming was performing with near perfection, only to sleep until disturbed (Fig. 3), exemplify the difficulties in motivating prairie dogs. This may not be explained by satiation, since performance was resumed as in moments prior.

Mange, as before, was easily excited and was prone to respond at high rates (Fig. 3) or to cease when apparently frustrated. She was the only dog to show overt "mediating" behavior (Laties, Weiss, \& Weiss, 1969) during the interval. This consisted of pacing in a circle around the chamber, but the return was typically too early to permit a reinforced response. Ming and Mary usually spent the interval motionless. Ming sometimes lowered her head and appeared to sleep during the interval. Late in DRL training Mange became increasingly excitable and performed with moderate efficiency only on DRL $5 \mathrm{sec}$. As even this performance became irregular, Mange weakened and died of dehydration. 5

Mary did not perform consistently but was not aroused by failures to obtain reinforcements. He did not sleep during sessions although he often stopped responding to wander about the chamber. His DRL performance (Fig. 2) shows little evidence of improvement of response/reinforcement ratio.

In sum, water became a critical motivator for the dogs, but performance under its control was inconsistent. Rubin \& Brown (1969) have found that the rabbit, a mammal of similar size, is notable for its unpredictability of responding and a wide range of individual differences. The rabbit is also somewhat problematic in regard to food but not water deprivation. With either food or water deprivation, the prairie dogs performed reliably only within a seemingly narrow band of deprivation values. Deviations produced dormancy or sluggishness. Prairie dogs may well be capable of sophisticated discriminative performance if optimally motivated. This must include drive state as well as contextual considerations as Cynomys are extremely labile where competing stimuli are present. Perhaps Cain \& Carlson (1968) have the answer in a WGTA situation. Their article, however, concentrates on color perception and does not describe learning behaviors. At the least, the prairie dog requires a considerable investment as a laboratory tool compared to a variety of other rodents we have "laboratorized."

\section{ADDENDUM}

The Problem of Water Needs

Cynomys are generally independent of drinking water, but one $S$ in the DRL experiment died of dehydration. We have observed that other rodents adapted to semiarid habitats become vitally dependent upon drinking water once induced to drink water in the laboratory (Boice \& Witter, 1970).

Table 1 lists results of a procedure that measured water needs of the prairie dogs. Dogs were individually placed in an operant chamber (Lehigh Valley, with enclosure) where sunflower seeds were freely available but water drops $(0.05 \mathrm{cc})$ were earned on a fixed-ratio (FR) schedule (Boice, 1969). At moderately high ratios (e.g., 32 barpresses to each drop of water), the $\mathrm{S}$ had moderate thirst or extra work as alternatives (Logan, 1964). The premise is that unrestricted intake of water exceeds needs $; 6$ thus, at moderate ratios enough work is required to limit intake to needs. Laboratory rats handle FR 32 with ease, but Ming and Mary earned little water at those terms. Ming died of dehydration following 3 days of FR 32 . The paradox is that the prairie dogs became dependent upon drinking water but were apparently unwilling to work on any terms but the easiest to meet that need. We have found that desert rodents react passively to stress by not responding. This may be a factor in the results of this study, but the unnatural dependence of the captive prairie dogs on drinking water may be germane. The finding that some xeric rodents (including Meriones) become "waterholics" in captivity suggests a search for physiological (e.g., kidney) changes that accompany the transition.

\section{REFERENCES}

ANTHONY, A. Behavior patterns in a laboratory colony of prairie dogs, Cynomys ludovicianus
Journal of Mammalogy, 1955, 36, 67-78.

BOICE, R. Water intake as a function of ease of access in Neotoma. Journal of Mammalogy, $1969,50,605-607$

BOICE, R., \& WITTER, J. A. Water deprivation and activity in Dipodomys ordii and Meriones unguiculatus. Journal of Mammalogy, 1970 (in press).

CAIN, R. E., \& CARLSON, R. H. Evidence for color vision in the prairie dog (Cynomys ludovicianus). Psychonomic Science, 1968, 13, 185-186.

JOHNSON, G. E. Observations on young prairie-dogs (Cynomys ludovicianus) born in the laboratory. Journal of Mammalogy, 1927, $8,110-115$.

KING, J. A. Social behavior, social organization, and population dynamics in a black-tailed prairie dog town in the Black Hills of South Dakota. Contributions from the Laboratory of Vertebrate Biology, 1955, 67, 1-123.

KOFORD, C. B. Prairie dogs, whitefaces, and blue gramma. Wildlife Monographs, 1958, No. 3, 1-78.

LATIES, V. G., WEISS, B., \& WEISS, A. B. Further observations on overt "mediating" behavior and the discrimination of time. Journal of the Experimental Analysis of Behavior, 1969, 12, 43-57.

LOCKARD, R. B. The albino rat: A defensible choice or a bad habit? American Psychologist, $1968,23,734-742$.

LOGAN, F. A. The free behavior situation. In D. Levine (Ed.), Nebraska Symposium on Motivation. Lincoin: University of Nebraska Press, 1964. Pp. 99-128.

REYNIERSE, J. H., SCAVIO, M. J., \& SPANIER, D. Interaction of hunger and thirst in Mongolian gerbils. Journal of Comparative \& Physiological Psychology, 1970, 70, 126-135.

RUBIN, H. B., \& BROWN, H. J. The rabbit as a subject in behavioral research. Joumal of the Experimental Analysis of Behavior, 1969, 12, 663-667.

SMITH, R. E. Natural history of the prairie dog in Kansas. University of Kansas Miscellaneous Publications, 1958, 16, 1-36.

YOUNG, S. P. Sketches of American wildlife. Baltimore: Monumental Press, 1946. NOTES

1. Personal communication.

2. Which they eat only as a last resort

3. Koford's observation that prairie dogs "... need not be caged, if the owner does not object to chewed woodwork [p. 9]" was replicated.

4. We were somewhat unskilled at sexing the dogs when names were assigned.

5. Confirmed by necropsy examination, University of Missouri Veterinary Medical Diagnostic Laboratory, Case No. 925-70.

6. Mean ad lib water intake of the two doys housed individually for the 20 days preceding this final experiment: Mary $-164 \mathrm{cc} /$ day (mean body weight $=1,640 \mathrm{~g}$ ); Ming $-92 \mathrm{cc} /$ day (mean body weight $=1,358 \mathrm{~g}$ ). Two of the untamed dogs that typically do not have drinking water drank less over the same period: Wildog $-18 \mathrm{cc} /$ day (mean body weight $=$ $1,544 \mathrm{~g}$ ): Goofy $-5 \mathrm{cc} /$ day (mean body weight $=$ $982 \mathrm{~g})$. 